\title{
Corpos nus de mulheres negras: eixos poéticos e políticos da escrita de mulheres africanas lusófonas
}

\author{
Catarina Isabel Caldeira Martins $^{1}$ (iD 0000-0002-431 7-9835 \\ 'Universidade de Coimbra, Departamento de Línguas, Literaturas e Culturas, Faculdade \\ de Letras, Coimbra, Portugal.3004-530-gabdiretor@fl.uc.pt
}

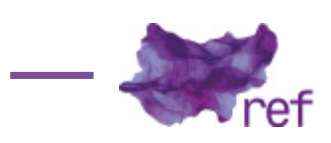

Resumo: Nos países africanos, o poder colonial encontrou nos corpos nus das mulheres negras um instrumento axial para o exercício material e simbólico da apropriação e violência. As corporalidades eram discursivamente construídas para legitimar uma ordem social codificada por gênero e raça. Nos projetos anticoloniais e das independências, os corpos nus de mulheres negras também são instrumento discursivo fundamental de um poder que agora é negro, mas permanece masculino e patriarcal, e que igualmente os objetifica, domina, expropria, controla e violenta. Importa, pois, considerar os modos em que as mulheres negras contestam esta expropriação e resistem a estas violências através de vozes incisivas que reclamam os seus corpos. Mulheres escritoras e poetas criam novas gramáticas poéticas nas quais ostentam as suas feminilidades, a sua nudez e a pele negra como o verdadeiro locus de articulação da violência e da resistência.

Palavras-chave: África, PALOP, literatura de mulheres, corpos femininos e negros

Black women's naked bodies: Poetic and Political Axes of African Women's Literature Abstract: In African countries in general, colonial power found in black women's naked bodies an axial instrument for the material and symbolic exercise of violence and appropriation. Embodiment was discursively constructed to legitimate the imposition of a social order codified by race and gender. As anticolonial and independence projects were built for these countries, again black women's naked bodies were handled as a fundamental discursive instrument by a power which was now black, but still male and patriarchal, and that likewise objectified, dominated, expropriated, controlled and violated them. It is important, thus, to consider the ways in/by which black women contest this appropriation and resist this violence through incisive voices that reclaim their bodies. Women writers and poets create new poetic grammars to display their femininities, their nakedness and their marked black skin as the true locus of articulation of violence and resistance.

Keywords: Africa; PALOP; women's literature; black women's bodies

\section{Corpos negros e nus de mulheres na política e na poética do colonialismo: abismos dentro de abismos}

"Femme nue, femme noire [...], Je te découvre, Terre promise..."'

Nos países africanos, em geral, e nos países africanos de língua oficial portuguesa, em particular, o colonialismo encontrou nos corpos nus das mulheres negras um instrumento concreto e retórico axial para o exercício material e simbólico das mais extremadas práticas de poder. Tendo como objeto a(s) mulher(es), reais ou metafóricas, estas práticas destinavam-se, sobretudo, à dominação dos homens brancos sobre os homens negros, segundo uma lógica em que as

' Excerto do poema "Femme Noire", publicado por Léopold Sédar SENGHOR em 1944. 
corporalidades eram discursivamente construídas para sustentar uma hierarquia civilizacional e legitimar a imposição de uma ordem social codificada segundo os eixos de género e de raça.

De facto, para lá da linha abissal que separa colonizador de colonizado, um espaço onde, como afirma Boaventura de SOUSA SANTOS (2007), só são válidas as lógicas da apropriação e violência, estas não são exercidas de forma homogénea. A ordem social sexuada do mundo colonizador é transferida, por imitação, para o mundo colonizado, no qual, como constata Maria LUGONES (2010), não havia "homens vs. mulheres", mas apenas "machos vs. fêmeas", uma vez que o estatuto de humanidade plena era reservado aos brancos. Desta forma, constrói-se uma hierarquia na qual as mulheres, meros corpos negros e nus, foram levadas ao extremo do despojamento que permite a máxima apropriação por todos os agentes de uma complexa rede de relações de poder, incluindo os próprios homens negros. Se estes homens também eram corpos aos dispor do colonizador, possuíam ainda a capacidade de expressão de posse sobre as suas mulheres. Nos corpos de fêmeas negras, a nudez aparece como a própria inscrição da alienabilidade, ou seja, trata-se de corpos que são definidos por um constante 'não-ser', manifesto na disponibilidade de utilização por parte de outrem, através de diferentes modos de exploração - do trabalho, do sexo e da reprodução. O modo de "haver" destes não mais que corpos nus é, por conseguinte, o modo da negação e da violência. Assinale-se que, na retórica lusotropicalista que sustenta o império português em particular, o enaltecimento da mestiçagem não é mais é do que o elogio da licença para violar (Hilary OWEN, 2007, p. 19).

Os corpos femininos, negros e nus aparecem, ainda, como eixo estruturante do discurso que sustenta esta ordem política colonial, constituindo o nó de um reportório simbólico e de uma gramática adaptáveis aos diferentes contextos em que, literalmente ou por analogia, é necessário firmar relações de poder assentes na intersecção de raça e género. Assim, a terra africana, virgem, núbil e fértil, que se oferece ao colonizador, aparece como o corpo feminino apropriável, sobretudo devido à exuberância selvagem e ao excesso sensual da sua Natureza. Estes atributos, por sua vez, são conferidos às mulheres negras, como Evas arquetípicas num heart of darkness que seduz inexoravelmente e ameaça, devendo, pois, ser domados. A estrita corporeidade destas fêmeas, no quadro do caos irracional dos territórios selvagens, forma o contraponto com a incorporeidade das mulheres brancas, paradoxalmente associadas a uma espiritualidade virtuosa e à pureza de Maria, mesmo na qualidade de mães. Esta oposição permite diferenciar os frutos de ventres brancos e negros, mesmo quando produto do mesmo sémen (uns, humanos; outros, sub-humanos), licencia a opressão de mulheres negras por mulheres brancas e responsabiliza as negras pelas sistemáticas violações. A gramática da diferença sexual serve, também, discursivamente, à caracterização do negro, ora efeminado, quando interessa destacar a inferioridade em relação ao homem branco, cuja espingarda e a tecnologia constituem um falo mais potente do que qualquer arma primitiva, ora hiperssexualizado, quando interessa sublinhar a sua natureza selvagem que a missão civilizadora deve neutralizar. Neste último caso, a apropriação da mulher negra por parte do homem branco chega a aparecer retoricamente como um acto bondoso de proteção daquela em relação à violência do negro. Na realidade, o que se pretende, com este acto, é a aniquilação do negro pela humilhação que constitui a ocupação violenta da "sua" mulher, numa contenda masculina em que a mulher serve apenas de objeto de disputa, cujo sofrimento não é sequer considerado. Assim, os corpos de mulheres negras fornecem o conjunto de atributos que permite configurar discursivamente mesmo as relações de poder entre homens, brancos e negros, ou do homem branco sobre a mulher branca. Desta forma, mesmo que sempre ausentes no seu 'não-ser', estes corpos possuem uma materialidade extremamente densa e ubíqua na poética e na política do colonialismo, a qual é sempre uma escrita e uma prática da violência nas formas mais extremas.

O facto de a lógica de apropriação e violência, manifesta no outro lado da linha abissal do colonialismo, ser diferenciada em termos de género torna-se clara quando atentamos aos projetos anticoloniais e das independências. Neste contexto, em que a cultura é mobilizada para consubstanciar ideias de nação e se torna crucial para a mobilização de uma ideia de povo, em particular nos anos que precederam e durante a luta armada, as noções de origem, de autenticidade, de tradição, são evocadas a partir de um reportório simbólico e poético associado à Mulher, consonante com a construção mítica da responsabilidade do movimento da Negritude. O poema Femme Noire (1944), de Léopold Sédar Senghor (Senegal), é o epítome da figuração da África num corpo negro e nu de mulher, Terra-Mãe-origem protectora e fecunda, ou terra-sensualidade arquetípica, cujas curvas e texturas reproduzem as paisagens de um território a ser possuído e fecundado pelo homem (Elleke BOEHMER, 2005, p. 24). Os homens são os sujeitos que escrevem, pelejam, se erguem virilmente como heróis sobre um objeto - o mesmo território-corpo feminino que o colono também cantara e possuíra. No discurso masculino, a Mulher mítica fornece um corpo (corpus) metafórico a uma poética de violência que sustenta as dominações sucessivas exercidas sobre as mulheres africanas. Mais do que isso: a exploração das mulheres reais chega a ser celebrada enquanto essência africana (e, portanto, naturalizada e não transformável): a da mulher rural da maternidade sucessiva e sacrificada, das cargas transportadas à cabeça e do filho amarrado às costas, da tradição etnicizada e de uma temporalidade primitiva, da ignorância, 
da oralidade, das línguas locais, uma mulher excluída das linguagens e das práticas da modernidade (OWEN, 2007, p. 21). De facto, é discursivamente criada uma dualidade sexuada que permite ancorar a identidade nacional africana em tempos remotos, através das representações do feminino e, simultaneamente, apresentá-la como protagonista de uma modernidade urbana, através das representações do masculino como o Homem Novo do discurso marxista, que se propagou em Angola e em Moçambique (OWEN, 2007, p. 34) - os casos de que aqui me ocuparei. Este Homem Novo, supostamente desetnicizado e sem sexo e, por isso, igualitário, servirá como base política para a conceção de um corpus jurídico que configura uma cidadania moldada pelo masculino e consagra a supremacia dos homens nos direitos e nas práticas sociais. Assim, no contexto da libertação do colonialismo, mais uma vez os corpos nus de mulheres negras são manuseados como um instrumento discursivo fundamental de um poder que agora é negro, mas permanece masculino e patriarcal, e que igualmente os objetifica, domina, expropria, controla e violenta. A linha abissal última desloca-se, assim, para a fronteira entre homens negros e mulheres negras.

\section{Abissalidades na crítica sobre as literaturas africanas: para 0 reforço de uma perspetiva feminista}

Nesta construção de uma ideia de nação e de povo como instrumento fundamental da luta contra o colonizador, a literatura desempenhou um papel fulcral. Por essa razão, o cânone e a periodização estabelecidos pela crítica desde a descoberta das literaturas africanas de expressão portuguesa mantêm a vinculação ao projeto nacional como parâmetro definidor. Ou seja, o que determina inclusões e exclusões no cânone, atribuições de valor, leituras de sentido, e que, surpreendentemente, continua, ainda hoje, na pós-colonialidade, a suscitar os maiores debates na crítica, mais do que critérios especificamente estéticos determinados pela produção textual em concreto, é a história política da nação (o combate anticolonial, a formação nacional), assim como os conceitos de "angolanidade" e de "moçambicanidade" (a criação de identidades para os novos sujeitos históricos) que denota uma forte marca não somente ideológica, mas também, por vezes, racial e étnica, para além de um fortíssimo recorte patriarcal - nos protagonistas e nas temáticas. Como afirma Hilary Owen (2007) relativamente a Moçambique:

The process of imagining Mozambican national unity over the last half century has never followed a uniform, consistent, or stable cultural pattern. It has, however, been predominantly the project of male thinkers, writers, politicians, revolutionaries, and literary critics drawing extensively, and unquestioningly, on a gendered figurative repertoire (p. 15).

De facto, no que diz respeito a Moçambique, as sínteses de história literária mais recentes e a periodização proposta preservam um foco na escrita da nação e da História e na construção anticolonial e nacionalista de uma moçambicanidade normativa, a partir do projeto marxista da Frelimo, na qual a literatura e a respetiva validação canónica, por instituições políticas ou do sistema literário, tiveram papel fundamental. Assim, Fátima MENDONÇA (2008) propõe uma periodização em três fases, que designa de: 1) "Ser Africano e Ser Europeu (Protonacionalismo)" do início aos anos 30 do séc. XX; 2) "Ser Africano vs. Ser Europeu (Negrismo / Negritude) - anos 40 a 60); 3) "Ser Nacional vs. Ser Universal (tendências variadas pós-independência)" (p. 22). Esta periodização corresponde sensivelmente à de Francisco Noa (2008) que, na mesma coletânea de artigos, Moçambique: Das Palavras Escritas (Margarida C. RIBEIRO; Paula MENESES, 2008), identifica os seguintes momentos: "Protonacionalismo" (até aos anos 30), "Nacionalismo" (anos 40-50) e "Poesia de Combate" (anos 60), uma fase de "transição" (anos 70) e, finalmente, o pósindependência (a partir de meados dos anos 80 ). ${ }^{2}$

Igualmente, no que diz respeito a Angola, encontramos ainda nas sínteses de história literária mais recentes a periodização já tradicional, para os séc. XX e XXI, em sensivelmente três fases: 1) o nativismo / nacionalismo (anos 40-60); 2) As independências (anos 60-70) ou "A geração da utopia", segundo o título do romance de Pepetela; 3) o pós-independência ou pós-colonialismo - dos anos 80 à atualidade, ou a "geração das incertezas", segundo proposta de Luís KADJIMBO (2015). Os debates debruçam-se sobre a fixação do momento fundacional da literatura angolana (Paula TAVARES, 2008), consonantes com as prioridades de um pensamento ainda focado sobre o nacionalismo, e os títulos destas sínteses da história da literatura angolana preservam as formulações tradicionais - "Literatura Angolana, suas Cartografias e seus Embates contra a Colonialidade" (Laura Cavalcante PADILHA, 2008) ou "Narrando a Nação: da retórica colonial à escrita da história"

\footnotetext{
2 Já Ana Mafalda LEITE, que parte de uma comparação com o caso brasileiro, prefere identificar apenas dois períodos na literatura moçambicana, ancorados numa fronteira de história política: $O$ "Período Anterior à Independência" e 0 "Período Pós-Independência" (LEITE, Ana Mafalda. "Tópicos para uma História da Literatura Moçambicana". In: RIBEIRO, Margarida C.; MENESES, Paula. Moçambique: das palavras escritas. Porto: Afrontamento, 2008. p. 48), acabando por tratar de modo detalhado apenas o primeiro, com uma estrutura que decalca a que fora proposta pelos dois críticos anteriores.
} 
(Inocência MATA, 2008) - mesmo que com ligeiros deslocamentos de perspetivas que permitem incluir a reflexão sobre os processos de construção da história (TAVARES, 2008) ou a dimensão da distopia, incorporada no percurso da Literatura Angolana elaborado por Inocência Mata em 2015, o qual contempla e organiza de forma semelhante a periodização acima descrita.

Esta colagem da literatura a um fazer e a um devir histórico de ordem política, construído discursivamente em moldes androcêntricos e, consequentemente, uma arena dos homens, tem consequências no modo como a escrita de mulheres ainda não alcançou verdadeiramente um lugar mais do que pontual e episódico em margens estanques de cânones com um cariz fortemente rígido. De facto, nas sínteses acima referidas, as mulheres ou são apresentadas como objetos da escrita masculina; ou, enquanto sujeitos da escrita, ora não merecem menção, ora merecem menção episódica en passant, como é o caso da pioneira moçambicana Noémia de Sousa (já Alda Lara, de Angola, tende a desaparecer) e, no período pós-independência, da poeta angolana Paula Tavares (PADILHA, 2008, p. 68; MATA, 2008, p. 84; Carmen Lúcia Tindó SECCO, 2008, p. 128) e da romancista moçambicana Paulina Chiziane, as quais são arrumadas, com duas palavras, como escritoras que tratam "a mulher" (NOA, 2008, p. 41-42) "o erotismo", ou "o individual" (algo que surge como demeritório no quadro de um cânone literário que sempre privilegiou a ideia de coletivo).

Isto significa que, muito embora exista, para o conjunto das literaturas lusófonas, uma preocupação crescente com as questões de género e estudos em número e monta suficiente sobre escrita de mulheres para contrariarem este lugar subalterno, dos quais gostaria de salientar os de Laura Padilha, Inocência Mata e Hilary Owen (para o caso específico de Moçambique), a historiografia literária preserva a definição do conjunto destas literaturas como um continuum de atos políticos assente na tradicional configuração masculina do imaginário histórico das narrativas nacionalistas, o qual urge questionar a partir de uma forte crítica feminista e a partir da escrita de mulheres. ${ }^{3}$ Sem uma interrogação da dimensão sexuada dos próprios processos de construção do cânone e da periodização destas literaturas, sem prosseguir, com um profundo recurso à epistemologia feminista, caminhos críticos como, por exemplo, o sugerido por Mata, noutra síntese recente: "A (sobre)valorização da função político-social da literatura" (MATA, 2015, p. 17) (note-se que o "sobre" está ainda entre parênteses). Inevitavelmente, as mulheres escritoras estarão presentes, no máximo, numa espécie de prateleira própria - a prateleira de "género" ou da "literatura de autoria feminina" (MATA, 2015, p. 24), um capítulo à parte identificado com consistência apenas a partir dos anos 80 do séc. $X X$, sem verdadeiramente interferirem com o cânone, nem provocarem uma revisão do reportório temático ou de ideias que sustenta esse mesmo cânone, a periodização e os critérios subjacentes às narrativas da historiografia literária.

Nesta perspetiva, Inocência Mata (2007) é desafiadora e explícita no que diz respeito à necessidade de desconstrução do cânone:

[...] proponho que se persiga a trajectória literária de mulheres cuja produção não apenas teve um papel fundamental na construção de um imaginário de resistência fundacional das diversas nacionalidades, ainda quando a escrita literária era subsidiária da construção da nação política e cultural, como na transformação desse sistema no período pós-colonial. Ora, sendo este período caracterizado por uma subjectivização enunciativa, pela internalização do olhar sobre as relações de poder e por uma auto-reflexividade, desse processo de ab-rogação resultaria uma mudança - diria até uma implosão - do lugar cristalizado da figura da mulher na literatura. [...] Esta questão de trajectória literária no feminino tem, assim, tanto a ver com o que escrevem as mulheres - afinal, veremos que escrevem sobre o que os homens escrevem! - como com o modo de ler o que as mulheres escrevem, isto é, as estratégias de leitura instrumentalizadas pela categoria do género a fim de fazer do acto da leitura uma mediação contra a centralidade de um sujeito flexionado por um único género, o masculino. [...] Neste processo de busca, a primeira questão parece-me ser a construção de um pensamento sobre a necessidade de tornar visíveis questões sociais cujos agentes são femininos. Por esse processo de desvelamento se chega à promoção de uma cultura de equidade e a uma cidadania participativa, através do desenvolvimento de estratégias de leitura que desnaturalizem a injusteza da permanência de um cânone que alia ao seu poder regulador o poder de exclusão. A história das mentalidades preocupa-se em explicar ausências [...], porém a inflexão do status quo acontece quando se desvelam os mecanismos de exclusão (p. 423).

Esta proposta é absolutamente imprescindível, enferma, porém, de algumas contradições que apontam para a necessidade do reforço de um travejamento com as epistemologias e a crítica feminista. Se, por um lado, se dessacraliza e "desnaturaliza" o cânone e o identifica como produto e produtor de relações de poder, que urge revelar; ou seja, se identifica como urgência a desconstrução de "estratégias de leitura" masculinas que atribuíram sentidos ao que escreveram

\footnotetext{
${ }^{3}$ Este é o objectivo de Owen (2007) em relação às escritoras moçambicanas: "...the present volume aims to explore how Mozambican women writers have worked within the spaces opened up by discourses of nationhood in order to appropriate and transform their principal figurative tropes and to call into question the gendered power relations that underpin them" (p. 15-16).
} 
os homens e as mulheres e ao modo como estes sentidos configuraram inclusões e exclusões, Mata preserva, aqui como em textos posteriores, a periodização tradicional, acima descrita, da historiografia das literaturas africanas, admitindo, para os períodos iniciais, que "a produção de mulheres", sendo escassa, "teve um papel fundamental na construção de um imaginário de resistência fundacional" - algo que nunca foi negado, antes instrumentalizado, pelo cânone tradicional, no que diz respeito às poetas da fase nacionalista, inclusivamente elidindo, lendo de forma enviesada ou omitindo modos particulares de reconfiguração de tropos masculinos. ${ }^{4} \mathrm{~A}$ expressão "veremos que as mulheres (também) escrevem sobre o que os homens escrevem!" acaba por colocar a bitola de referência nos homens, ao mesmo tempo em que, nas páginas seguintes, dedicadas ao único período que, na perspetiva da autora, causa a "transformação do sistema" - o período pós-colonial --, as estratégias de leitura parecem orientadas por um apriorismo de pendor essencialista sobre o que é "feminino". Mata (2007) registra, a partir dos títulos de uma série de obras líricas e narrativas de mulheres, o seguinte:

Com efeito, estes títulos revelam, à partida, uma diferente perspetiva, esta subjetiva, porque vivencial e intimista [...]. As vozes femininas da actualidade, não descurando a dimensão comunitária, já prenunciam uma busca individual, mais íntima e sonhadora, mesmo quando a sua preocupação última é colectiva [...] estes títulos são sintagmas que indiciam, à partida, um itinerário individual, uma percepção dos lugares subjectivos da vida, das faces esconsas do ser, uma percepção de teor sensorial, que evidencia um caminho para a complexidade do indivíduo, feito de corpo e espírito... (p. 425).

De um ponto de vista feminista, que há muito insiste na afirmação de que o "privado é também público", é difícil compreender uma separação entre uma escrita da História do coletivo (masculina), e uma escrita intimista, do individual ou do "corpo amoroso" (feminina), que parece sustentar, na crítica sobre escritoras, a identificação de uma profusão de vozes líricas de mulheres de Angola, a partir dos anos 80 , com muito parcas menções a romancistas. Já em Moçambique, em que, nas gerações atuais, é usual a referência a apenas três ficcionistas - Lília Momplé, Lina Magaia e, claro, Paulina Chiziane -, e não surge nenhuma voz lírica, também a esta escrita raramente é reconhecida uma dimensão pública que transcenda as problemáticas da "condição feminina", as quais acabam banalizadas como questões de ordem secundária e que não alteram a configuração básica do corpus da literatura nacional.

A ideia fundamental de Mata - a da promoção de uma cultura de equidade - necessita, por isso, de um aprofundamento da dimensão feminista da crítica, inclusivamente numa perspetiva autorreflexiva. Esta deve dirigir-se aos próprios pressupostos discursivos da constituição das narrativas da história literária e das hermenêuticas que as informam, de modo a permitir, realmente, desfazer "bordas", "margens" (PADILHA, 2007) e mecanismos de construção da diferença que as próprias leituras focadas na visibilização das mulheres e adjetivadas no "feminino" (conceito problemático para a epistemologia feminista devido ao seu potencial essencialista), por mais fundamentais que sejam, acabam, malgré-elles, por produzir.

A própria ideia de História em que o estudo das literaturas africanas assenta é estruturada sobre pilares epistemológicos ocidentais que as expressões culturais africanas tradicionalmente contrariaram: desde logo, uma noção linear e teleológica de tempo e de progresso, em que o passado tem menos peso do que, por exemplo, os cultos da ancestralidade, no âmbito de temporalidades circulares ou de espaços/tempo que se interpenetram; a preocupação com a factualidade e a menor atenção ao universo mítico, com a correspondente focalização em territórios materiais, cartografados, e não em espaços imaginados, flutuantes, nómades, híbridos; a História como sucessão de linhas de conflito geralmente dicotómicas (colonizador / colonizado; branco / negro), e de eventos políticos e guerreiros, entre outros. A esta construção da História e da nação, em particular em países como Angola e Moçambique, que sofreram duas longas guerras, corresponde toda uma gramática masculina da violência, estruturada em torno de heróis e mártires masculinos e valores másculos como a força, a valentia, a resistência, validando-se lugares de memória associados às conquistas da força ou ao tombar do corpo masculino. Acresce a virilidade alimentada, entre outros, pela satisfação sexual encontrada no corpo sempre disponível das mulheres. Nestas narrativas, das quais um exemplo significativo é, talvez, Pepetela, a apropriação do corpo feminino através da violação, que surge recorrentemente nalguns dos seus mais emblemáticos romances, como Mayombe (1980) ou A Geração da Utopia (1992), aparece sob uma óptica idealizada que jamais perturba a legitimidade moral dos heróis. O corpo feminino existe em função do guerreiro ou converte-se na natureza em que este mergulha para renovar as forças para o combate pela nação. Assim, devemos interrogar não somente as ausências de vozes femininas, mas os próprios modelos epistemológicos androcêntricos que sustentam a hermenêutica textual. Estes convertem a crítica literária em agente ativo destas ausências, validando um cânone

\footnotetext{
${ }^{4}$ Ver o capítulo dedicado à Noémia de Sousa por Hilary Owen e a forma como não somente a obra como a figura da poeta são apropriadas por uma leitura nacionalista e masculina do tropo da maternidade que sustenta a sua "canonização" (OWEN, 2007, p. 44-45).
} 
e uma periodização em que as vozes femininas, enquanto sujeito, não podem ter lugar. Ou seja, enquanto as mulheres permanecerem adstritas ao 'não-ser' de corpos nus, disponíveis como material poético para a dominação masculina, o seu lugar na escrita será também um 'nãolugar' ou um lugar eternamente marginal.

É preciso, pois, que "as incertezas" das gerações pós-coloniais angolanas e moçambicanas, um período apresentado como de diversidade, heterogeneidade, contradições, tensões, multiplicidades identitárias e expressivas, potenciado pelas distopias relativas aos projetos das independências, sejam alargadas como metodologia de questionamento aos períodos anteriores, como sugere Owen (2007, p. 22) relativamente ao caso moçambicano. O objetivo é o resgate de vozes e camadas de sentido que, preservando essas heterogeneidades e tensões, as evidencie como emergências epistemologicamente transformadoras (SANTOS, 2007). As literaturas africanas, oriundas de territórios que a modernidade ocidental, com a sua racionalidade universalizante, pretendeu anular culturalmente, devem ser desvendadas como fontes férteis de novas mundivisões e saberes que permitam o pensamento crítico de alternativas à modernidade, ao invés de verem este potencial anulado por espartilhos reproduzidos das epistemologias coloniais e patriarcais.

\section{Corpos de mulheres negros e nus - reescritas resistentes}

O corpo de mulher, negro e nu, surge, pois, como o elemento central de uma poética da violência que sustenta discursivamente toda uma estrutura de dominação masculina. As mulheres escritoras africanas reconhecem claramente este facto e convertem o mesmo corpo no eixo de poéticas da resistência, invertendo, desde logo, o objeto que é escrito (possuído, dominado) no sujeito que escreve. O confronto intertextual e a reescrita da poética masculina, que passam, inevitavelmente, pela reescrita da própria violência a partir de uma posição radicalmente outra, constituem, assim, um momento essencial para o resgate e a reivindicação desse corpo, e para a reinscrição das mulheres numa História e num corpo nacional através de narrativas com protagonistas e topoi completamente distintos. A título de exemplo, cito dois poemas de Paula Tavares e Ana de SANTANA (1985) (Angola) e alguns elementos dos romances Niketche. Um História de Poligamia (2002) e O Alegre Canto da Perdiz (2008), de Paulina CHIZIANE (Moçambique). ${ }^{5}$ Estes textos constituem uma disputa pelo espaço, pelo tempo, e por um dizer do coletivo no sentido de, justamente, rever as linhas semânticas e as lógicas discursivas androcêntricas e ocidentais (e, nesse sentido, coloniais) da História e da identidade angolana e moçambicana. Estas escritoras partem de uma ressignificação do corpo feminino e negro, ostentando a sua nudez como forma de negar a sua expropriação e objetificação, e apropriando-se dele não só como acto individual ou de um coletivo exclusivamente feminino, mas porque o identificam, com toda a justeza, como a matéria concreta e simbólica sobre a qual foram construídos os edifícios discursivos consubstanciadores de relações de poder no decorrer de um longo processo histórico. O corpo de mulher, negro e nu, sempre disputado, aparece como arma de cisão de corpora institucionalizado (o corpo nacional, o corpus do cânone literário, os corpos emblemáticos de papéis sociais normativos), de modo a criar fissuras em que se inscrevam camadas de espaços concomitantes e de tempos coevos, até aqui silenciados e ocultados.

Começo por Paula Tavares e o seu primeiro livro, Ritos de Passagem (1985), o qual interpreto como uma proposta de reinscrição do corpo feminino e negro no "ser" real e no tempo. De um modo que só aparentemente se reduz à expressão de anseios e desejos individuais, Tavares revela, afinal, que este corpo sensualizado foi e é o próprio território do político e que o erótico explícito e ousado, que perpassa todo o volume de poemas, é um princípio de poder que transcende o privado e se revela profundamente emancipador. Como defende uma das principais teóricas do feminismo africano, Patricia McFADDEN (2003), da Suazilândia, a partir das ideias de Audre Lorde, o poder político do erótico manifesta-se particularmente em África, em que a sexualidade feminina foi, como se disse, não apenas reprimida, mas objeto de apropriações e violências materiais e discursivas várias, inclusivamente através daquelas narrativas masculinas que, ao mesmo tempo em que constroem o feminino como lugar de preservação da tradição, interrompem a continuidade feminina dos legados das antepassadas sobre a indissociabilidade de prazer e poder.

For the majority of black women, the connection between power and pleasure is not often recognised, and remains a largely unembraced and undefended heritage. Yet an understanding of this connection is one of the most precious legacies passed on to us by our foremothers. In often obscure or hidden ways, it lies at the heart of female freedom and power; and when it is harnessed and "deployed", it has the capacity to infuse every woman's personal experience of living and being with a liberating political force (MCFADDEN, 2003).

\footnotetext{
${ }^{5}$ Farei apenas uma breve menção a Niketche, que analiso mais longamente em Martins (2015), para me concentrar em O Alegre Canto da Perdiz, cuja abertura focalizada num corpo nu de uma mulher negra inspirou esta reflexão.
} 
Evoco apenas dois poemas. Em "Alphabeto", o eu lírico identifica claramente o corpo feminino como constante produto de uma escrita alheia, ciclicamente recomposto.

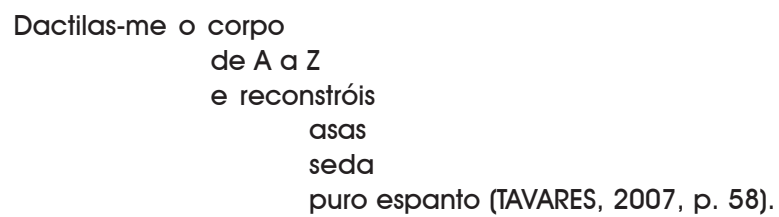

A dactilografia, um percorrer táctil da pele-superfície de escrita, é só na aparência uma escrita libertadora. As asas que esta reescrita abre não permitem superar inscrições anteriores, fazendo surgir uma pluralidade de cicatrizes.

Por debaixo das mãos enquanto abertas

Aparecem pequenas as cicatrizes (TAVARES, 2007, p. 58).

Trata-se de um corpo-palimpsesto-objeto, ainda entregue às mãos de um "tu" que, no poema "Desossaste-me" (TAVARES, 2007, p. 54), é evocado num tom de acusação pela dimensão de violência inerente à recomposição escrita. Esta desenvolve-se como atos sucessivos de desmembramentos e inscrições num universo Outro ao sujeito da enunciação - o universo masculino -, em relação ao qual o corpo feminino representa um conjunto de antíteses: ferida e prótese, maldita e necessária.

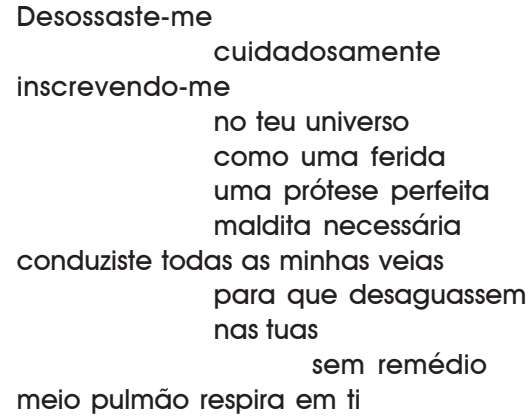

o outro, que me lembre

mal existe (TAVARES, 2007, p. 54).

O texto decorrente desta inscrição é inexoravelmente aquele que serve uma totalidade construída pelo masculino, que se institui como teleologia do feminino, reduzindo-o a um estatuto de 'não-ser'. Até que, num momento muito forte de rutura, o corpo feminino completo e vivo (aceso), que usa os próprios instrumentos de inscrição (tacula), recusa o papel subserviente materializado nas tarefas domésticas e na reclusão e reclama, em maiúsculas, a voz incisiva, o poder de decisão, a sua libertação e um estatuto de sujeito.

\author{
Hoje levantei-me cedo \\ Pintei de tacula e água fria \\ o corpo aceso \\ não bato a manteiga \\ não ponho o cinto \\ VOU \\ para o sul saltar o cercado (TAVARES, 2007, p. 54).
}

Enquanto o primeiro poema parece remeter para um tempo iterativo inexorável de alienação do corpo feminino exposto à inscrição de violências repetidas, o segundo opera uma cisão nesta continuidade temporal e espacial do universo-Todo-homem, reclamando para o Eu enunciador um momento iniciático e uma geografia própria. O tempo é também iterativo, mas no sentido da repetição contínua do gesto de emancipação. Em ambos os poemas, o corpo e o sentir não são meramente individuais nem evocam apenas o coletivo das mulheres. Acima de tudo, confrontam as estruturas discursivas patriarcais da construção cultural, as suas axialidades espácio-temporais, e a desmaterialização do corpo feminino, negro e nu, numa mitificação que serve o poder patriarcal. De resto, o conjunto do volume desenvolve-se sob o signo da "passagem" para uma outra escrita 
do corpo já nem feminino nem masculino, em que as metáforas são despidas da semântica rígida que possuíam no corpo retórico da "africanidade" para se abrirem a deslocamentos e transformações num espaço sempre transicional e de tradução. Os sangues vertidos pelas mulheres (menstruação, desvirgindação, parto, violação), por exemplo, passam a ocupar o lugar central em "cerimónias de passagem" que asseguram a unidade cultural num tempo elíptico, substituindose aos sangues dos heróis homens conquistadores num tempo linear, como no poema "Colheitas", estruturado em torno dos 28 dias do ciclo menstrual, ou no poema "Cerimónia de Passagem", que abre o livro com uma ideia expressa de circularidade da vida, na qual o recorte inicial é constituído pelos sangues vitais das mulheres ("a rapariga provou o sangue / o sangue deu fruto").

Também no poema de Ana de Santana intitulado "Canção para uma Mulher", incluído em Sabores-Odores \& Sonho (1985), há uma rutura com as vozes que cantam uma mulher, para nelas se fazer ouvir a voz silenciada que nunca pode falar de si nos seus próprios termos:

\author{
Nunca me falaste \\ da tua música \\ estuprada à força do falo, \\ nem me contaste \\ das partículas que pacientemente raspaste \\ ao sol para fecundar a terra. \\ apenas dizes dos braços \\ cruzados à volta do filho \\ ou do milho a colher (SANTANA 1985, p. 20).
}

O dizer do corpo feminino é um canto silenciado de uma violência sexual interiorizada e restringe-se à expressão amputada da maternidade sofrida e do trabalho rural. $O$ ato de fecundação é atribuído a mulheres sem homem, um momento fundacional que carece ainda de bocas femininas libertas e de filhos que inscrevam o corpo feminino não como recetáculo, mas como verdadeiro agente do ato de criação, mesmo quando este resulta do "estupro" que metonimicamente designa toda a violência real e simbólica exercida sobre o corpo das mulheres.

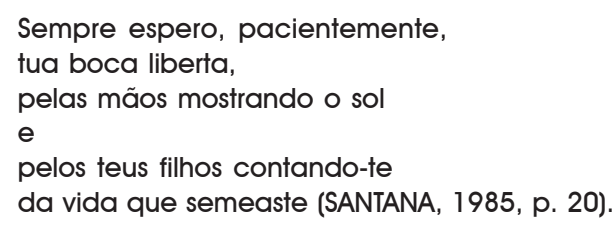

De resto, no poema "Ralhete" (SANTANA, 1985, p. 15), que inscreve habilmente a guerra num espaço onde público e privado não se distinguem, não encontramos apenas a voz de uma mãe que admoesta severamente o filho que reclama dela funções maternais tradicionais, mas a interpelação de todo um horizonte de expetativas relativamente ao que é a mulher-mãe-África, em particular num contexto de conflito que problematiza as identidades estruturantes da unidade nacional construída na literatura patriarcal. O corpo feminino enquanto tropo é, mais uma vez, decomposto em partes que recusam o papel servil que exerciam na construção ideológica masculina. A cisão com esta construção é localizada, expressamente, na apresentação do ato da fecundação como violação, que impede a concretização da maternidade nos termos que a deviam definir. $O$ Eu feminino que afirma que

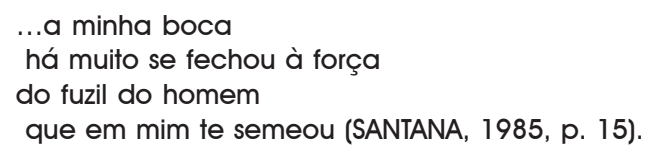

é, paradoxalmente, neste registro de "ralhete", uma voz fortíssima, em que dor é indissociável de resistência, vontade e decisão. Um sujeito, e nunca uma vítima.

Portanto, estas poetas questionam, com a sua escrita, não apenas o que é narrado no corpus da cultura, mas o modo da narrativa, os seus topoi e as posições de sujeito / objeto, agente / paciente, os tempos e os espaços que nela se concretizam. Atente-se neste belíssimo passo de Niketche (2002), de Paulina Chiziane (2002):

Nós, mulheres, fazemos existir, mas não existimos. Fazemos viver, mas não vivemos. Fazemos nascer, mas não nascemos. Há dias conheci uma mulher do interior da Zambézia. Tem cinco filhos, já crescidos. O primeiro, um mulato esbelto, é dos portugueses que a violaram durante a guerra colonial. O segundo, um preto, elegante e forte como um guerreiro, é fruto de outra violação dos guerrilheiros de libertação da mesma guerra colonial. O terceiro, outro mulato, mimoso como um gato, é dos comandos rodesianos brancos, que arrasaram esta terra para 
aniquilar as bases dos guerrilheiros do Zimbabwe. O quarto é dos rebeldes que fizeram a guerra civil no interior do país. A primeira e a segunda vez foi violada, mas à terceira e quarta entregouse de livre vontade, porque se sentia especializada em violação sexual. O quinto é de um homem com quem se deitou por amor pela primeira vez.

Essa mulher carregou a história de todas as guerras do país num só ventre (p. 277-278).

Desta forma concentrada, Chiziane reconta a História nacional a partir dos corpos das mulheres. Estas são geralmente excluídas não somente da noção heroica de combatentes, da resistência persistente do quotidiano da retaguarda, como até da história da dor. Mártires são os homens que tombam, mas nunca mulheres como esta, que Chiziane resgata. O corpo negro desta mulher tem gravada em si a História do seu país, onde as mulheres são a substância e a permanência numa inconstância de homens. O corpo negro deixa de ser metáfora e a mitificação é anulada através da crueza de uma realidade excessivamente violenta. Para além disso, não se mostra uma mulher vítima. O conceito de vítima é ressignificado na forma como a mulher recupera a propriedade e a capacidade de ação do seu corpo usurpado e se torna criadora de uma nova raça por actos de resistência e amor. Esta raça moçambicana é inevitavelmente mestiça, pois os conflitos da história nunca resultam em separação, mas em histórias misturadas que jamais conseguirão dissociar-se. A História não é uma linha só com um fim único, mas uma trama materializada nos corpos e pelos corpos de mulheres em que linhas convergem, se cruzam e divergem, perfazendo uma cartografia complexa, paradoxal.

Uma intenção semelhante à do passo citado de Niketche é a que vemos desenvolvida em O Alegre Canto da Perdiz (2008), que conta a História de Moçambique da perspetiva de três mulheres de três gerações da mesma família, do período colonial, passando pelas guerras e construindo a utopia de um país pacificado e conciliado. A narrativa começa com a aparição inusitada de uma mulher negra e nua, junto dos montes Namuli, na província da Zambézia, que são associados à origem do mundo. De seguida, o romance desenvolve-se em dois planos. Um deles é uma série de lendas que reescrevem o domínio do mítico, em paralelo com o da História, numa ótica de mulheres heroicas. A Zambézia, metonímia de Moçambique, é retratada como feminina, uma terra fértil cobiçada pelos "marinheiros" - os colonizadores brancos. Se se mantém a típica associação da mulher à terra africana, a construção de Moçambique aparece, porém, como uma contenda sexuada, um paradoxo de desejo e violência, prazer e dor, cujo centro e agente são as mulheres. Os seus corpos violentados, como no poema de Ana de Santana, são o lugar sofrido da criação de "uma nova raça". Também os corpos femininos vertem sangues, mas a sua heroicidade assenta numa ação criadora e unificadora radicalmente inversa ao ato masculino, destruidor e traidor. O erotismo e a sensualidade femininos e masculinos surgem como uma vivência coletiva, como forças moventes da História, e não como expressão de um desejo subjetivo:

De todas as sereias, a Zambézia era a mais bela. Os marinheiros invadiram-na e amaram-na furiosamente, como só se invade a mulher amada. A Zambézia bela, encantada, gritava em orgasmo pleno: vem, marinheiro, ama-me, eu te darei um filho. Eu e tu, sempre juntos, criando uma nova raça. [...] Os navegadores correram de aldeia em aldeia, derramando sangue, profanando túmulos, pervertendo a história, fazendo o impensável. A Zambézia abriu o seu corpo de mulher e engravidou de espinhos e fel. [...] Havia lógica em tudo aquilo. O homem apaixonado tudo arrasa para possuir a mulher amada. É a vida. Primeiro o prazer do amor, na gestação da dor. Com enjoos e vómitos para temperar a gravidez. O corpo transformado, rasgado, ferido. O sangue fluindo, no parto da nova nação (CHIZIANE, 2008, p. 64).

O outro plano diegético é uma enorme analepse que conta o passado de Maria das Dores, o corpo nu exposto na abertura do romance, e, sobretudo, da sua mãe Delfina, a personagem mais complexa da narrativa. Nela se encontram as contradições das intrincadas dimensões de poderes em conflito no colonialismo e nos caminhos para a independência. Dotada de uma beleza e de uma sensualidade incomparáveis, Delfina cedo tem consciência de que o seu corpo feminino e negro representa o degrau mais baixo da subalternidade. Ainda adolescente, é vendida pela mãe, Serafina, que a prostitui, revelando como o corpo feminino negro é também um bem de troca num sistema colonial em que racismo e sexismo são indissociáveis de capitalismo. A compreensão deste sistema e da elevada cotação do seu corpo perfeito e irresistível faz com que Delfina encontre nele o instrumento que usa conscientemente para sair de um lugar de dominada para exercer poder de dominação. Por isso, Delfina recusa a sua condição de negra, exprimindo uma obsessão por se tornar branca - condição que se materializa em privilégios de classe e modos de vida, para lá da cor da pele. Através da prostituição e do casamento com um colono branco, Delfina torna-se rainha e poderosa, como o romance repetidamente sublinha:

Era uma mulher com voz de perdiz, ululando triunfos no miradouro do mundo, dançando nua no ponto mais alto do monte. Espalhando pela atmosfera cheiro de erotismo, de sexo, cheiro de pornografia cafreal. Os olhos do mundo perguntaram ao mesmo tempo:

- Quem és tu que galgas as encostas do monte com a leveza da luz e ululas triunfos nas 
montanhas de glória?

- Eu sou Delfina, a rainha!

- Quem te coroou rainha da noite?

- Vivo no alto, sou rainha, sou mulher de homem branco.

Dizem que o mundo inteiro se iluminou de espanto (CHIZIANE, 2008, p. 222).

Este retrato de Serafina e Delfina problematiza o retrato típico da Mãe Negra, sacrificada e abnegada, mesmo que miserável e sujeita a todo o tipo de violências, incluindo a apropriação alheia dos frutos do seu ventre, encarados como mera força produtiva na lógica económica do colonialismo. É esta violência sobre o corpo feminino, reduzido a instrumento de reprodução de "mão de obra" escrava, que legitima a sua reapropriação e a sua conversão numa arma para a libertação da opressão. A figura da prostituta, tão habitual nas narrativas masculinas (Florence STRATTON, 1994, p. 42; Catarina MARTINS, 2011, p. 124), é aqui muito mais problematizada, sobretudo porque a mulher se torna agente, e não objeto, do uso que faz do seu corpo, e desaparece o olhar patriarcal sobre um "corpo corrompido". Delfina é proprietária de um capital que investe no sentido da ascensão social e da aquisição de poder. Trata-se do exercício calculista de uma estratégia assente no conhecimento das relações sociais, económicas e políticas, bem como das diversas articulações de raça, classe social e sexo dentro do colonialismo, conforme negociações diversas, das quais não se exclui o afeto e a sexualidade.

Na casa do colono Soares passam a conviver um casal racialmente misto, os filhos negros do primeiro casamento de Delfina com o negro José dos Montes, e os mulatos do segundo. Esta casa representa um Moçambique que o colonialismo torna inevitavelmente híbrido e antecipa a utopia plurirracial dos últimos capítulos do romance (contrariando as lógicas das narrativas nacionalistas anticoloniais ou as construções de homogeneidade racial e étnica). Porém, a mãe negra, ao contrário do pai branco, maltrata os filhos negros, privilegiando os mulatos. Desta forma, através de Delfina, e de José, assimilado e sipaio, Chiziane trata a problemática da reprodução do sistema colonial pelos próprios negros e negras. A crueldade de Delfina é reforçada pelo choque entre o seu comportamento e a ideia de maternidade africana (o colo sofrido que alberga todas as raças). O sistema colonial, sustentado nos eixos de raça e de sexo, que Delfina soube, de início, manipular a seu favor, acaba por engoli-la. Abandonada e sem dinheiro, Delfina vende a virgindade de Maria das Dores, torna-se dona de um prostíbulo e, arrependida da sua conduta, procura desesperadamente a filha negra.

Maria das Dores, por sua vez, é vendida pela mãe, sofre os maus-tratos do marido num lar polígamo e foge, levando os filhos pequenos que perde num Moçambique em guerra. É, como a mulher de Niketche, um corpo prostituído, violentado, de muitos sangues. É um mapa físico, traçado por cicatrizes, de uma deambulação solitária e desesperada pelo território do país, numa procura pelos filhos que é também a procura pela identidade de um povo. Maria das Dores contradiz e complexifica as representações típicas da mulher africana: mãe que dá à luz, mas cuja maternidade é o martírio de um ventre e um coração expoliados pela perda daqueles que gerou; corpo nu, mas não virgem, nem núbil - um corpo repetidamente penetrado, libertado paradoxalmente pelo sofrimento extremo. Um corpo que transporta um poder de transformação, obriga a um olhar novo sobre conflitos, divisões e caos:

Colocámos os pretos e os brancos na batalha das raças, mas eles tanto se bateram até que se beijaram. E se apaixonaram pela bravura de um e de outro. Acabaram casados, numa só paixão, formando uma só família [...]. No final desta guerra seremos um. Esses filhos metade pretos, metade brancos, metade asiáticos, serão os fósseis a partir dos quais se compreenderá a nossa História. Nas próximas gerações as raças se amarão, sem ódio nem raivas, inspiradas no nosso exemplo. [...] Terá chegado o momento de inventar novas raças e recriar novas humanidades (CHIZIANE, 2008, p. 333-334).

Com esta conclusão, Chiziane faz uma reavaliação da História em que os heróis e as valentias são perspetivados com matizes vários. Procede-se à reinscrição das mulheres no papel de criadoras, cujos corpos são entendidos como armas e locus de combate, e cujos sangues - das violações e dos partos - são reconhecidos como sangues igualmente vertidos pela pátria. Esta reinscrição é colocada em oposição à destruição motivada pelo ímpeto de conquista violenta de colonizadores e resistentes anticoloniais, materializado nas guerras sucessivas. Para além disso, o corpo feminino negro e nu, aparecido junto dos montes Namuli, a que o romance regressa no final como um colo materno original, converte-se no momento utópico de unidade nacional através da criação de uma identidade mestiça para Moçambique.

A subalterna, a quem foi negada voz, disputa um espaço de fala para contar as experiências vividas pelas mulheres, a especificidade das opressões e violências que sofreram no colonialismo, no processo de constituição dos novos países e na pós-colonialidade. Os seus corpos deixam de ser metáfora para se mostrarem de uma forma muito assertiva como um terreno de disputa no qual o poder e a violência se inscreveram sempre de forma profundamente material. As mulheres que escrevem tornam claro que estas sujeitas nunca foram passivas, tendo, pelo contrário, desenvolvido 
estratégias várias de resistência e de afirmação que obrigam a uma leitura muito mais complexa dos processos históricos do colonialismo e das independências do que a matriz teleológica e heroica androcêntrica do Novo Homem africano. As estruturas e dinâmicas sociais e políticas dos territórios africanos colonizados e dos países independentes surgem, nas obras escritas por mulheres, como mais intrincadas, com cruzamentos e camadas insuspeitados, nomeadamente por factores raciais e sociais se intersectarem com variadas dimensões sexuadas. Neste reclamar da História por parte das escritoras africanas, os corpos femininos, negros e nus erguem-se e obrigam a uma nova compreensão de si, de quem os oprimiu, e das relações entre ambos. Obrigam, finalmente, a uma nova perceção e a uma nova linguagem para uma narrativa Outra da História e da memória nacionais, em que se deslocam a semântica e o valor de conceitos estruturantes como opressão, submissão, conquista, heroísmo e sangue. A matéria simbólica da qual se constrói a nação será só aparente a mesma e, no entanto, radicalmente invertida.

\section{Referências}

BOEHMER, Elleke. Stories of Women. Gender and Narrative in the Postcolonial Nation. Manchester and New York: Manchester UP, 2005.

CHIZIANE, Paulina. Niketche. Uma História de Poligamia. Lisboa: Caminho, 2002.

CHIZIANE, Paulina. O Alegre Canto da Perdiz. Lisboa: Caminho, 2008.

KADJIMBO, Luís. "Breves reflexões sobre a Geração das Incertezas. A Geração literária angolana do período pós-independência (1980-2001)". Textos e Pretextos, Lisboa, n. 19, p. 27-37, 2015. (Angola. Poesia e Prosa)

LUGONES, Maria. “Toward a Decolonial Feminism”. Hypatia, v. 25, n. 4, p. 742-759, 2010.

MARTINS, Catarina. "'La Noire de...' tem nome e tem voz. A narrativa de mulheres africanas anglófonas e francófonas para lá da Mãe África, dos nacionalismos anticoloniais e de outras ocupações". E-Cadernos CES, n. 12, p. 119-144, 2011.

MATA, Inocência. "Mulheres de África no Espaço da Escrita: A Inscrição da Mulher na Sua Diferença". In: MATA, Inocência; PADILHA, Laura C. A Mulher em África. Vozes de uma margem sempre presente. Lisboa: Colibri, 2007. p. 421-440.

MATA, Inocência. "Narrando a nação: da retórica anticolonial à escrita da história". In: PADILHA, Laura C.; RIBEIRO, Margarida C. Lendo Angola. Porto: Afrontamento, 2008. p. 75-85.

MATA, Inocência. "A Literatura Angolana entre Utopias e Distopias: Um Percurso". Textos e Pretextos, Lisboa, n. 19, p. 9-26, 2015. (Angola. Poesia e Prosa)

McFADDEN, Patricia. "Sexual Pleasure as Feminist Choice". Feminist Africa, n. 2, 2003. Disponível em: http://agi.ac.za/sites/agi.ac.za/files/fa_2_standpoint_1.pdf. Acesso em: 02/02/2018.

MENDONÇA, Fátima. "Literaturas Emergentes, Identidades e Cânone”. In: RIBEIRO, Margarida C.; MENESES, Paula. Moçambique: das palavras escritas. Porto: Afrontamento, 2008. p. 19-33.

NOA, Francisco. "Literatura Moçambicana: os trilhos e as margens". In: RIBEIRO, Margarida C.; MENESES, Paula. Moçambique: das palavras escritas. Porto: Afrontamento, 2008. p. 35-46.

OWEN, Hilary. Mother Africa, Father Marx. Women's Writing of Mozambique 1948-2002. Lewisburg: Bucknell University Press, 2007.

PADILHA, Laura Cavalcante. "Bordejando a margem (escrita feminina, cânone africano e encenação de diferenças)”. In: MATA, Inocência; PADILHA, Laura C. A Mulher em África. Vozes de uma margem sempre presente. Lisboa: Colibri, 2007. p. 469-487.

PADILHA, Laura Cavalcante. "Literatura Angolana, suas Cartografias e seus Embates contra a Colonialidade". In: PADILHA, Laura C.; RIBEIRO, Margarida C. Lendo Angola. Porto: Afrontamento, 2008. p. 57-73.

RIBEIRO, Margarida C. e MENESES, Paula. Moçambique: das palavras escritas. Porto: Afrontamento, 2008.

SANTANA, Ana de. Sabores-Odores \& Sonho. Luanda: União dos Escritores Angolanos, 1985. 
SANTOS, Boaventura de Sousa. "Para além do Pensamento Abissal: Das linhas globais a uma ecologia de saberes". Revista Crítica de Ciências Sociais, n. 78, p. 3-46, outubro 2007.

SECCO, Carmen Lúcia Tindó. "Entre Passos e Descompassos, a Alquimia e a Resistência do Canto - reflexões sobre a poesia angolana hoje". In: PADILHA, Laura C.; RIBEIRO, Margarida C. Lendo Angola. Porto: Afrontamento, 2008. p. 125-133.

STRATTON, Florence. Contemporary African Literature and the Politics of Gender. London and New York: Routledge, 1994.

TAVARES, Paula. "Contar Histórias". In: PADILHA, Laura C.; RIBEIRO, Margarida C. Lendo Angola. Porto: Afrontamento, 2008. p. 39-50.

TAVARES, Paula. Ritos de Passagem. Lisboa: Caminho, 2007.

Catarina Isabel Caldeira Martins (catarina.martins@fl.uc.pt) é doutora em Letras, Professora Auxiliar do Departamento de Línguas, Literaturas e Culturas da Faculdade de Letras da Universidade de Coimbra e investigadora do Centro de Estudos Sociais. Foi leitora, durante vários anos, na Universidade Cheikh Anta Diop de Dakar. É doutora em Literatura Alemã pela Universidade de Coimbra (2008). Tem publicado sobre temas de estudos feministas e pós-coloniais, literatura comparada, literatura de expressão alemã e literaturas africanas, em particular de mulheres. De entre as suas actuais áreas de investigação destacam-se os estudos pós-coloniais e os estudos feministas, associados a temas e problemáticas das literaturas e culturas. É docente em programas de Doutoramento em Estudos Feministas, Estudos Pós-Coloniais e Estudos de Literatura e Cultura.

\section{COMO CITAR ESSE ARTIGO DE ACORDO COM AS NORMAS DA REVISTA}

MARTINS, Catarina Isabel Caldeira. "Corpos nus de mulheres negras: eixos poéticos e políticos da escrita de mulheres africanas lusófonas". Revista Estudos Feministas, Florianópolis, v. 27, n. 1, e58880, 2019.

\section{CONTRIBUIÇÃO DE AUTORIA}

Todo o trabalho.

\section{FINANCIAMENTO}

Faculdade de Letras da Universidade de Coimbra

CONSENTIMENTO DE USO DE IMAGEM

Não se aplica

APROVAÇÃO DE COMITÊ DE ÉTICA EM PESQUISA

Não se aplica

CONFLITO DE INTERESSES

Não se aplica

LICENÇA DE USO

Este artigo está licenciado sob a Licença Creative Commons CC-BY. Com essa licença você pode compartilhar, adaptar, criar para qualquer fim, desde que atribua a autoria da obra.

\section{HISTÓRICO}

Recebido em: 29/08/2018

Aprovado em: 07/09/2018 